Bioscientia Medicina: Journal of Biomedicine \& Translational Research

Journal Homepage: www.bioscmed.com

\title{
The Relationship between Plasma Hypocretin Levels and Sleep Disorders in Patients with Parkinson's Disease
}

\author{
Ahmad Afdal ${ }^{*}$, Syarif Indra ${ }^{2}$, Hendra Permana ${ }^{2}$ \\ ${ }^{1}$ Fellowship Student Neurology, Faculty of Medicine, Universitas Andalas, Padang, Indonesia \\ 2 Department of Neurology, Faculty of Medicine, Universitas Andalas, Padang, Indonesia
}

\section{A R T I C L E I N F O}

\section{Keywords:}

Parkinson's disease

Hypocretin

Sleep Disorders

\section{*Corresponding author:}

Ahmad Afdal

\section{E-mail address: \\ ahmadafdal2911@gmail.com}

All authors have reviewed and approved the final version of the manuscript.

https://doi.org/10.32539/bsm.v5i9.350

\begin{abstract}
A B S T R A C T
Background: There are many areas of brain degeneration in people with Parkinson's disease. The dopaminergic degeneration process in the midbrain causes early symptoms of sleep disturbances. Hypocretin produced by the hypothalamus is involved in the pathophysiology of Parkinson's disease. Some research results regarding the relationship between plasma hypocretin levels and sleep disorders in patients with Parkinson's disease are still controversial. Method: This research is a cross sectional study in Neurology Polyclinic Dr. M. Djamil Padang and Network Hospital. All research subjects measured hypocretin levels and sleep disorders using the Epworth Sleepiness Scale. Statistical analysis was performed on a computerized basis using IBM SPSS statistics version 23.0 for windows. Result: A total of 60 patients with Parkinson's disease were included in this study, 30 subjects experienced sleep disorders and 30 others had no sleep disorders. There was a significant difference in lower plasma hypocretin levels in the Parkinson's group with sleep disorders, namely $81.817 \pm 22.770$ and in the group without sleep disorders, plasma hypocretin levels were found to be $255.416 \pm 226.590(\mathrm{p}=0.000)$. There was no statistical difference in clinical degree, age, duration of illness between the Parkinson's group with sleep disorders and the group without sleep disorders $\mathrm{p}$ $>0.05$ Conclusion There is a significant difference in hypocretin levels against the sleep disorder group in people with Parkinson's disease. In this study, there was no association between age, clinical degree of Parkinson's disease, and duration of Parkinson's disease and sleep disturbances. Degeneration in the olfactory bulb area, hypothalamus, and brainstem can precede dopaminergic degeneration in the midbrain and cause sleep disturbance symptoms.
\end{abstract}

\section{Introduction}

Parkinson's disease is the second most common neurodegenerative disease after Alzheimer's dementia. Characterized by classic motor symptoms, namely bradykinesia, rigidity, and tremor, and non-motor symptoms, one of which is sleep disturbance. Throughout the course of the disease, almost all sufferers experience sleep-wake cycle disorders.1,2,3 Sleep disorders in Parkinson's disease reach 4090\%.4,5,6 This condition has an impact on severe disabilities and has a serious effect on the quality of life of the sufferer. ${ }^{3,7}$

Degeneration occurring in many areas such as the olfactory bulb, hypothalamus, and brainstem likely precedes the dopaminergic degeneration process in the midbrain causing the initial symptoms of Parkinson's disease in the form of anosmia and sleep disturbances. ${ }^{8}$

The hypocretin system is one of the neurochemicals produced in the hypothalamus which is involved in the pathophysiology of Parkinson's disease, especially contributing to sleep disturbances, daytime sleepiness. Hypocretin, also known as orexin, is a neuropeptide hormone that is expressed by a number of neuron cells in the dorsolateral hypothalamus. Hypocretin is secreted by the lateral and posterior hypothalamic neuron cells. This hormone regulates various physiological functions such as sleep-wake cycles, cardiovascular response, heart rate and 
hypertension.9,10,11 Hypocretin concentrations and neuron-producing neurons have lower levels in patients with Parkinson's disease than normal individuals, as seen in the identification of a reduction in the number of hypothalamic hypocretin neuron cells post-mortem which is recognized as the gold standard and this hypocretin level is associated with the degree of Parkinson's disease. Some of the variables of this disease that are often found to be associated with sleep disorders in Parkinson's disease include the duration of the disease, the age of the patient, the severity of motor manifestations, depression, cognitive impairment and non-tremor dominant motor phenotype, although not all epidemiological data show the same association.12,13

Many studies have been conducted to determine the role of hypocretin in sleep disorders in people with Parkinson's disease. Thannickal et al (2007) reported loss of hypocretin neurons in patients with Parkinson's disease. Another publication found by Baumann et al (2005) and other research groups reported that a large proportion of sleep disturbances are associated with Parkinson's disease such as narcolepsy such as sleep attacks and nocturnal insomnia but also REM sleep behavior. In previous studies on narcolepsy, the loss of hypocretin cells causing symptoms was 91\% (86-94\%) on average at the age of 41 years (31-51) years. ${ }^{14}$ The available published data do not define a limit on the extent of hypocretin cell loss at the onset of narcolepsy symptoms or whether hypocretin cell loss is progressive after the onset of narcolepsy. However, studies on the relationship between hypocretin cell loss and the severity of narcolepsy symptoms including cataplexy, hallucination, sleep paralysis, REM sleep behavior disorder, daytime sleep attacks and nocturnal insomnia are relatively few with limited conclusions. ${ }^{15}$ Cerebrospinal fluid hypocretin (CSF) levels in experimental studies in mice were not linearly associated with the loss of hypocretin cells, but $56-86 \%$ loss of hypocretin cells in mice indicated a sleep abnormality. ${ }^{16}$ The loss of hypocretin cells in narcolepsy patients is accompanied by a decrease in the innervation of cells in the group receiving hypocretin. ${ }^{17}$ Several studies have also reported that hypocretin levels are normal in the early stages of Parkinson's disease. Fronczek et al and Drouot et al (2003) reported that CSF hypocretin levels were decreased in the ventricular system in patients with Parkinson's disease. ${ }^{12}$

Several research results regarding the relationship between plasma hypocretin levels and sleep disorders in patients with Parkinson's disease are still unsatisfactory, due to the many controversial findings. For this reason, the authors intend to conduct a study to determine the relationship between plasma hypocretin levels and sleep disorders in patients with Parkinson's disease.

\section{Method}

This research is a cross sectional study in Neurology Polyclinic Dr. M. Djamil Padang and Network Hospital. The inclusion criteria were patients with Parkinson's disease who had been diagnosed based on clinical symptoms and were willing to take part in the study. The exclusion criteria were having a history of systemic disease in the form of anemia, diabetes mellitus, thyroid gland disease, kidney failure / uremia, liver disease, and malignancy with / without a history of chemotherapy. 2) are taking drugs that have a sedative effect (for example, antihistamines, muscle relaxants, etc.) in the past week, 3) have a history of head injury, brain infection, brain tumor or other abnormalities in the brain, 4) Drop out with reason anything.

Parkinson's disease was assessed based on neurological examination with Hoehn and Yahr's measurement results grades 1-5. The Epworth sleepiness scale is used to measure a patient's general level of daytime sleepiness or average sleep tendencies in daily life. The Epworth Sleepiness Scale is a simple questionnaire based on retrospective reports of the likelihood of falling asleep or falling asleep in a variety of different situations. ESS is a questionnaire that assesses a person's sleepiness level consisting of eight questions that must be answered with a semantic scale value. The ESS value $\leq 10$ is considered normal and the ESS value> 10 is considered disturbed. ${ }^{18}$ In all study subjects, hypocretin levels were measured by the ELISA method in the Biomedical Laboratory of FK UNAND 
Padang.

Statistical analysis was performed on a computerized basis using IBM SPSS statistics version 23.0 for windows. The first time a univariate analysis was carried out to obtain data on the characteristics of the research subject. After that, the analysis was carried out using the unpaired T-test statistical test to obtain a relationship between the independent variable (plasma hypocretin levels) and the dependent variable (sleep disorders in patients with Parkinson's disease).

\section{Results}

There were 60 patients with Parkinson's disease who were consecutively collected and included as research subjects. The mean age of the 60 subjects was $63.42 \pm 8.373$ years, with an age range of 35 to 77 years. Male sex (33 people, $55 \%$ ) was more in this study with the most clinical degrees at grade $2 \mathrm{H} \& \mathrm{Y}(38.3 \%)$ and the mean duration of disease was $6.07 \pm 4.737$ years.

The subjects of this study were 60 people, consisting of 30 patients with Parkinson's disease with sleep disorders and 30 patients with Parkinson's disease without sleep disorders. It was found that plasma hypocretin levels were lower in the Parkinson's group with sleep disorders, namely $81.817 \pm 22.770$ and in the group without sleep disorders, the plasma hypocretin levels were $255.416 \pm 226.590$. It was found that the difference in plasma hypocretin levels was statistically different with a value of $\mathrm{p}=0.000$

Based on the degree of severity, there were 6 people (10\%) with 1 H\&Y clinical degree, 23 people (38.3\%) with 2 H\&Y clinical degrees, 19 people (31.7\%) with 3 H\&Y clinical degrees, 10 people (16.7\%) with clinical degree $4 \mathrm{H} \& \mathrm{Y}$, and as many as 2 people (3.3\%) with clinical degree $5 \mathrm{H} \& \mathrm{Y}$. There was no statistical difference in clinical degree between the Parkinson's group with sleep disorders and the group without sleep disorders with $\mathrm{p}=0.390$

The mean age of people with Parkinson's disease with sleep disorders was $64.43 \pm 6.725$ and the mean age of people with Parkinson's disease without sleep disorders was $62.40 \pm 9.761$. With the Mann-Whitney test, there was no statistical difference in the mean age between the Parkinson's group with sleep disorders and the group without sleep disorders with $\mathrm{p}=0.871$.

The mean duration of disease in the Parkinson's group with sleep disturbances was $6.30 \pm 5.70$ years and the mean duration of disease was $5.83 \pm 3.61$. With the Mann-Whitney test, there was no statistical difference in the duration of illness between the Parkinson's group with sleep disorders and the group without sleep disorders with $\mathrm{p}=0.726$

\section{Discussion}

In this study, there were differences in the mean plasma hypocretin levels of Parkinson's patients with sleep disorders and without sleep disorders. When compared, the plasma hypocretin levels of the Parkinson group with sleep disorders were lower. Hypocretin-1 and -2 / orexin-A and -B neuropeptides (HCRT-1 and -2 / OX-A and -B) play an important role in sleep-wake regulation. The HCRT / OX system regulates sleep-wake control through a complex interaction between the monoaminergic / cholinergic (wake-up) nervous system and gamma-aminobutyricergic (sleep-inducing) acid. ${ }^{19}$

Hypocretin is specifically a dorsal and lateral hypothalamic neurotransmitter that functions to regulate sleep, appetite and energy use. ${ }^{20}$ The final cause of sleep disorders, especially EDS in Parkinson's disease is not known with certainty, but factors such as dopaminergic treatment, motor disability or degenerative disease processes are involved. The existence of sleep disorders that resemble narcolepsy in Parkinson's disease, some researchers suspect that the same mechanism is between narcolepsy and EDS in Parkinson's disease. ${ }^{21,22}$ Low levels of hypocretin in cerebrospinal fluid are typical in cases of narcolepsy, but in some studies, levels are normal in some cases of Parkinson's disease. ${ }^{23}$ Drouot et al in a study using cerebrospinal fluid from the ventricles showed low hypocretin levels in cases of Parkinson's disease. ${ }^{24}$ Two recent pathological studies reported a reduction in hypocretin cells in the hypothalamus in people with Parkinson's disease. 12,25

Hypocretin deficiency causes a loss of sleep-wake control or stability with the result of an unstable 
transition between wakefulness to nonREM and REM sleep. ${ }^{19}$ In this study it was found that Parkinson's patients with sleep disorders had lower hypocretin levels than Parkinson's patients without sleep disorders. A similar study by Wernicke et al showed a decrease in hypocretin levels in the cerebrospinal fluid of Parkinson's patients. ${ }^{11}$

In this study, there was no difference in the clinical degree of patients with Parkinson's disease with sleep disorders and without sleep disorders with a value of $p$ $=0.390$. This is inversely proportional to the results of previous studies where the decrease in hypocretin levels is directly proportional to the degree of severity. Thannickal et al. examined the hypothalamus of 11 patients with Parkinson's disease and 5 healthy controls to determine if there was hypocretin cell damage in Parkinson's disease. Immunostaining for hypocretin-1 revealed that loss of hypothalamic hypocretin neurons correlates with the clinical stage of Parkinson's disease (as measured by the Hoehn and Yahr scale). There are $23 \%$ in grade 1 disease and $62 \%$ in grade 5 disease. There is an association between loss of hypothalamic melanin-concentrated hormone $(\mathrm{MCH})$ neurons, which is interrelated with hypocretin neurons, and stage of disease. Hypocretin and $\mathrm{MCH}$ cells are completely lost from the anterior-posterior axis of the hypothalamus. ${ }^{25}$

There are several hypotheses that explain the different results in this study. Although the most widely recognized degenerative process in Parkinson's disease is the loss of dopaminergic neurons in the substantia nigra pars compacta ( $\mathrm{SNpc}$ ), the pathological cascade also occurs with widespread degeneration of many surrounding neurons which also contributes to insomnia and sleep disturbances. Degeneration in many areas such as the olfactory bulb, hypothalamus, and brainstem likely precedes dopaminergic degeneration in the midbrain, causing early symptoms of Parkinson's disease in the form of anosmia and sleep disturbances. The role of the hypothalamus in particular has a potential influence in the process of excessive sleep, many nuclei play a role in stimulating sleep and the resulting neurochemicals, including neurons that activate sleep in the ventrolateral and median preoptic areas.8 Dopaminergic neuron cells in the ventral tegmental-substantia nigra area receive input from hypocretin neuron cells in the hypothalamus and form a loops controlling pathway in the form of an ascending pathway through the thalamus and cortex and a descending pathway through the nucleus pedunculopontin and reticular formation, and it has been reported that there is a decrease in levels. hypocretin neurons and hypocretin levels in the cerebrospinal fluid and frontal cortex. 12,25 Braak et al. Suggested that the initial pathological process begins in the lower brainstem area and proceeds to the midbrain area and cortex. The concept of early pathology involving the brain stem can explain the non-motorized early symptoms of sleep disturbances in patients with Parkinson's disease. 26 This may also explain that there is no difference in clinical degrees of patients with Parkinson's disease with sleep disorders and without sleep disorders.

In this study, there was no difference in the age of patients with Parkinson's disease with sleep disorders and without sleep disorders with a value of $\mathrm{p}=0.871$. Several epidemiological studies have shown that sleeprelated complaints and daytime sleepiness are more common in older men and women than those of younger ages. Foley et al. Found that among 9.282 people aged 65 years or older, more than 50\% reported sleep disturbances. However, Grandner et al. With a larger surveillance study found that advancing age was not associated with increased sleep disturbance. These results suggest that the increase in sleep problems frequently reported with age is a nonlinear phenomenon, mediated by factors other than physiological aging. ${ }^{27}$

This study also reported similar results, in the Parkinson's patient population, age did not affect the presence or absence of sleep disorders. In this study, there was no difference in the duration of Parkinson's disease with sleep disorders and without sleep disorders. Thannikal et al also identified loss of neuromelanin-containing cells in the substantia nigra of patients with Parkinson's disease that correlated with disease duration. ${ }^{25}$ This cannot be proven in this study. The hypothesis that could explain this is a 
retropective study so that disease duration cannot be evaluated objectively or there is a potential for recall bias.

There is a significant difference in hypocretin levels against the sleep disorder group in patients with Parkinson's disease. Hypocretin hormone disruption causes loss of sleep-wake control or stability with the result of an unstable transition between wakefulness to nonREM and REM sleep.

\section{Conclusion}

There is a significant difference in hypocretin levels against the sleep disorder group in patients with Parkinson's disease. Hypocretin hormone disruption causes loss of sleep-wake control or stability with the result of an unstable transition between wakefulness to nonREM and REM sleep.

In this study, there was no association between age, degree of Parkinson's disease, and duration of Parkinson's disease and sleep disturbances. Degeneration in the olfactory bulb area, hypothalamus, and brainstem can precede dopaminergic degeneration in the midbrain and cause sleep disturbance symptoms. Dopaminergic neuron cells in the ventral tegmental-substantia nigra area also play a role in the wake-sleep system. In addition, the initial pathological process starting from the lower brainstem area and going to the midbrain and cortex areas can cause sleep disturbances in Parkinson's patients. On the other hand, the increase in sleep problems frequently reported with age is a nonlinear phenomenon, mediated by factors other than physiological aging. A large-scale prospective cohort study is still needed to assess the role of hypocretin in detail on sleep disorders in patients with Parkinson's disease and other factors that interact with sleep disorders.

\section{References}

1. Cheryl HW. Diagnosis and Management Parkinsons Disease. Profesional Communication Inc. 1999

2. Happe S, Baier PC, Helmschmied K, Meller J, Tatsch K, Paulus W. Association of daytime sleepiness with nigrostriatal dopaminergic degeneration in early Parkinson's disease. J Neurol.2007.254:1037-1043

3. PERDOSSI. Penyakit Parkinson dan Gangguan Gerak Lainnya. Buku Panduan Tatalaksana.2013

4. Alatriste-Booth V, Rodriguez-Violante $\mathrm{M}$, Camacho-Ordonez A, Cervantes-Arriaga A. Prevalence and correlates of sleep disorders in parkinson's disease: a polysomnographic study. Arq Neuropsiquiatr.2015.73(3):241-245

5. Suzuki K, Miyamoto M, Miayamoto T, Iwanami M, Hirata K. Sleep Disturbances Associated with Parkinson's Disease. SAGE-Hindawi Access to Research Parkinson's Disease;article.2011.ID 219056, 10 pages

6. Suzuki K, Miyamoto K, Miyamoto M, Numao A, Sakuta H, Fujita H et al. Sleep Disturbances in Patients with Parkinson's Disease. Chapter from the book: A Synopsis of Parkinson's Disease.2018.Downloaded from:

http//www.intechopen.com/books/asynopsis-of-parkinson's-disease.

7. Ylikoski A, Martikainen K, Sieminski M, Partinen M. Sleeping difficulties and healthrelated quality of life in Parkinson's disease. Acta Neurologica Scandinavia.2017.135(4),459-468.

8. Albers JA, Chand P, Anch AM. Multifactorial Sleep Disturbance in Parkinson's Disease. Sleep Medicine.2017.S1389-9457

9. Hagan JJ, Leslie RA, Patel S, Evans ML, Wattam TA, Holmes $\mathrm{S}$ et al. Orexin a activates locus coeruleus cell firing and increases arousal in the rat. Proc. Nat. Acad. Sci. USA.1999.96, 10911-10916.

10. Imperatore R, Palomba L and Cristino L. Role of Orexin-a in hypertension and obesity. Curr. Hypertens. Rep.2017.19:34

11. Wienecke M, Werth E, Poryazova R, BaumannVogel H, Bassetti CL, Weller $M$ et al. Progressive dopamine and hypocretin deficiencies in Parkinson's disease: is there an impact on sleep and wakefulness? J. Sleep Res.2012.21, 710-717. 
12. Fronczek R, Overeem S, Lee SY, Hegeman IM, van Pelt J, van Duinen SG et al. Hypocretin (orexin) loss in Parkinson's disease. Brain.2007.130, 1577-1585.

13. Yousaf T, Pagano G, Niccolini F, Politis $M$. Excessive daytime sleepiness may be associated with caudate denervation in Parkinson disease. J Neurol Sci.2018.387:220227.

14. Thannickal TC, Moore RY, Nienhuis R, et al. Reduced number of hypocretin neurons in human narcolepsy. Neuron.2000.27:469-74

15. Billiard M. Diagnosis of narcolepsy and idiopathic hypersomnia. An update based on the International Classificaion of Sleep Disorders, 2nd edition. Sleep Med Rev.2007.

16. Gerashchenko D, Murillo-Rodriguez E, Lin I, et al. Relationship between CSF hypocretin levels and hypocretin neuronal loss. Exp Neurol.2003.184:1010-6

17. Thannickal TC, Siegel JM, Moore RY. Pattern of hypocretin (orexyn) soma and axon loss, and gliosis, in human narcolepsy. Brain Pathol.2003.13:340-51

18. Gofir A, Astuti. Pemeriksaan Gangguan Tidur. Dalam buku Panduan Tatalaksana Gangguan Tidur.Ed 2. Editor: Islamiah WR. Jakarta:PERDOSSI. Sagung Seto.2018.hal 4162

19. Chow, M. and Cao, M. The hypocretin/orexin system in sleep disorders: Preclinical insights and clinical progress', Nature and Science of Sleep.2016.8, pp. 81-86. doi: 10.2147/NSS.S76711.
20. Ganjavi H, Shapiro CM. Hipocretin/ Orexyn : A Molecular Link Between Sleep, Energy Regulation and Pleasure. J. Neuropsychiatry Clin Neurosci.2007. 19:4;413-19

21. Arnulf I, Ferraye M, Fraix V, Benabid AL, Chabardes S, Goetz L, et al. Sleep induced by stimulation in the human pedunculopontine nucleus area. Ann Neurol.2010.67:546-9

22. Gjerstad M, Wentzel-Larsen T, Aarsland D, Larsen J. Insomnia in Parkinson's disease: Frequensy and progression over time. Journal of Neurology, Neurosurgery, and Psychiatry.2006.78(5).476-479

23. Baumann CR, Basetti CL. Hypocretins (orexins) and sleep-wake disorders. Lancet Neurol.2005.4;673-82

24. Drouot X, Moutereau S, Nguyen JP, Lefaucher JP, Creange A, Remy $\mathrm{P}$ et al.Low levels of ventricular CSF orexin/ hypocretin in advanced PD. Neurology .2003.61(4):540-543

25. Thannickal TC, Lai YY, Siegel JM. Hypocretin (orexin) cell loss in Parkinson's disease. Brain.2007.130(Pt 6):1586-1595

26. Braak H, Del Tredici K, Rub U, de Vos RA, Jansen Steur EN, Braak E. Staging of brain pathology related to sporadic Parkinson's disease. Neurobiol Aging.2003.24:197-211

27. Grandner, MA, Martin JL, Patel NP, Jackson NJ. 'Age and sleep disturbances among American men and women: Data from the U.S. Behavioral Risk Factor Surveillance System', Sleep.2012.35(3), pp. 395-406. doi: $10.5665 /$ sleep. 1704 . 